Article

\title{
The Effect of Gamification on Psychological and Behavioral Outcomes: Implications for Cruise Tourism Destinations
}

\author{
Byeong Cheol Lee
}

Department of Tourism and Event Management, Kyonggi University, Seoul 03746, Korea; 2bclee@kyonggi.ac.kr

Received: 24 April 2019; Accepted: 23 May 2019; Published: 28 May 2019

\begin{abstract}
The purpose of this study is to empirically examine the effect of gamification on tourist psychological outcome and knowledge gain in the context of cultural heritage sites, which are popular cruise tourism destinations. A comprehensive literature review revealed the critical role of gamification in facilitating psychological (enjoyment, flow experience, and loyalty) and behavioral outcomes (knowledge gain) at cultural heritage sites. Using a field experiment, this study employed a gamified app as a manipulation. A total of 342 gamified app users $(n=165)$ or non-users $(n=177)$ were selected by stratified random sampling method from among college students majoring in tourism and cruise management in South Korea. After screening the data, a Hayes' PROCESS modeling technique was mainly utilized to test the proposed hypotheses based on 331 cases. The results showed that gamification had a strong influence on knowledge gain about cultural heritage attractions. On the other hand, gamification had negative effects on enjoyment and flow experience. More importantly, gamification had a negative indirect effect on loyalty toward cultural heritage attractions. These findings imply the usefulness of gamified apps to convey memorable and real-time information and knowledge to users in cultural heritage sites.
\end{abstract}

Keywords: gamification; flow; enjoyment; knowledge gain; cruise tourism; cultural heritage site

\section{Introduction}

Cruise tourism is a fast-growing part of the tourism industry, attracting an ever-wider range of tourist demographics. Due to increasing cruise tourism with ships of ever-increasing size, cultural heritage sites in coastal areas have been popular cruise tourism destinations. Along with the rapid expansion of cruise tourists visiting cultural heritage sites, cruise companies are designing more variety of services through new technologies in order to address changing customer needs $[1,2]$. New technologies such as social media and smartphones provide technical tools for developing and designing memorable travel experiences. In particular, gaming or digital games (often called 'games') have penetrated our everyday lives and have now become a typical form of interactive entertainment which is enjoyed by consumers from all demographics [3]. With the rapid advancement of ICTs and mobile devices, digital games have become mobile, allowing dynamic, real-time interactions at the location of users [4,5]. This phenomenon has been titled "gamification", and its mechanics in non-gaming environments have become a fast-emerging practice in business, especially in the service industry [6].

Gamification refers to the use of game design elements like rewards, missions, rankings, and fun in non-game or business domains such as education, management, health care, and tourism [7]. It is widely accepted that gamification leads to the higher level of consumer participation and boosts unique experiences, as it facilitates access to additional services and opportunities, allowing participants to obtain further information and to increase dynamic interaction with others $[3,8]$. Due to the benefit of 
delivering knowledge or information through game design elements, gamification has been shown to be a useful practice in a tourism environment that needs to convey rather complex knowledge or expertise pertaining to cultural historical heritage sites or historical museums (e.g., [9-11]).

Inspired by the positive benefits of games, gamification has increasingly drawn the attention of academics and practitioners in diverse domains, especially in education and learning context [3]. Despite its increasing interest, less attention has been focused upon examining the effect of gamification in the context of tourism $[5,12,13]$. Notably, in the field of education and learning, there have been a number of experimental studies that have empirically tested the impact of gamifiedlearning methods on learning outcomes (e.g, grade) or motivational factors like enjoyment and flow (e.g., [14-17]). However, the majority of studies in the tourism field on gamification focus primarily on qualitative and descriptive approaches [5,13,18,19]. In particular, Koivisto and Hamari [3] recently conducted an in-depth literature review of 842 gamification-related studies. They found 276 empirical articles, of which only two were conducted in the culture and tourism context, showing that empirical research on gamification in tourism remains insufficient. Since gamification is a relatively new concept, it is mostly unclear how users like tourists respond to gamification design [7], and there is limited knowledge on how the benefits of gamification can be successfully applied to different business processes including to the tourism industry. In addition, indicating the lack of academic evidence of the effect or benefits of gamification, as Salen and Zimmerman [20] and others [13,21-23] have stressed, it has not yet been firmly established that gamification is appropriate for changing people's motivational behaviors or attitudes in all types of business processes. Thus, this gap in academic knowledge has made it difficult to achieve consensus on whether the impact of gamification on tourists in various types of destinations is positive or negative, and to predict its efficacy in a tourism context [24,25].

Therefore, this study attempts to empirically examine the effect of gamification on visitor motivational behavior, knowledge gain, and loyalty within the context of cultural heritage sites that commonly have difficulties communicating complicated historical knowledge. More specifically, this study employs an experimental design method to examine how gamification influences their motivational behavior, consisting of flow experience and enjoyment and knowledge gain, as well as loyalty toward cultural heritage sites, in a comprehensive process model based on the case of the Gyeongbok palace in South Korea. The research model examines the usefulness of gamified apps for determining psychological states such as levels of enjoyment and flow and knowledge gain, which, in turn, enhance the degree of loyalty toward cultural heritage attractions.

\section{Literature Review}

\subsection{Gamification in the Tourism Context}

Gamification is a design approach which is intended to increase motivation, enjoyment, and involvement with specific products and service users in non-game contexts; this approach has not yet been firmly established and is continually undergoing changes [12]. Game design elements are the basic components of gamification applications [26]. Gamification uses a variety of game design patterns. Werbach and Hunter [27] identified 15 typical game design elements; badges, rewards, leaderboards, feedback, missions, progress, etc. are the most commonly mentioned components.

Within the context of tourism, gamification is expected to increase tourists' satisfaction levels, as it provides better access to desired services and additional opportunities about need-based products and services, social recognition, effective time management, and virtual collaborative learning experiences while touring a destination. Gamification enhances services and systems by creating experiences which are similar to those created by games. These game-like experiences help support and motivate users to perform reasoned actions and behavior encompassing positive attitudes toward services, and to actively participate in learning activities $[7,22,28,29]$. More importantly, gamified practices allow individuals to experience enjoyment, flow, autonomy, mastery, and accomplishment through various game design elements such as missions and quizzes [18]. 
Inspired by the benefits of games, gamification has gained increased attention as an effective technology that attempts to further transfer these benefits to a variety of services and systems, and to further increase their autotelic nature within "non-gaming" contexts, such as tourism, but also education (e.g., $[16,17,30,31])$, health (e.g, [32-34]), work (e.g., [25,35,36]), marketing management (e.g., [8,19,37-39]), etc. Despite the fact that there have been some gamification-related studies in relation to tourism, most studies have focused primarily on understanding the role of gamification in qualitative approaches.

$\mathrm{Xu}$ et al. [18] suggested gamification as a new paradigm of mobile-based learning in the field of tourism. They also underlined design elements of gamification which can be employed as a means to enhance the scope of the technology's influence upon visitor motivation and behavior. Subsequently, Bulencea and Egger [19] conducted a comprehensive review of the literature on gamification. As a result, they proposed theoretical foundations and research directions for a gamification concept that can be applied to tourism research as an extension of conceptual frameworks. In their extended research, Negruşa, Toader, Sofică, Tutunea, and Rus [40] highlighted the role and function of gamification, enabling destination marketing organizations (DMOs) and tourism stakeholders (i.e., tourists, employees, and local communities) to receive economic, social, and environmental benefits in sustainable destination management.

In an empirical study, Sigala [13] proved the positive effects of gamification on motivational behavior (e.g., participation and involvement) and on psychological outcomes by comparing behavioral perception toward gamified app services between gamified app (TripAdvisor) users and non-users in a virtual community platform. Although not directly related to the effect of gamification, Yoo et al.'s study [41] investigated which factors affect the adoption of gamified applications within the context of tourism, and found that the hedonic characteristics of gamified apps are strong. By adopting TAMs (Technology Acceptance Models), Aguiar-Castillo et al. [42] verified the perceived usefulness and ease of use on tourist satisfaction levels and recycling behavior. Within the context of tourism, few studies have paid attention to empirical evidence of the effect of gamification on behavioral models, Thus, this study tries to develop a theoretical model of gamification to explore its impact on psychological and behavioral outcomes in a comprehensive process, based on a field experiment employing a newly-developed gamified app tailored for the Gyeongbok palace, a cultural heritage site.

\subsection{Research Model Building}

The usefulness of gamification lies notably in its ability to engage and excite; when playing games, users often experience enjoyment, competence, mastery, immersion, or flow, all of which are considered to be intrinsic motivational human factors [3,29]. Self-determination theory (SDT) is a commonly used theoretical framework by which to understand the motivational potential of games [18,43]. SDT emphasizes the fact that human motivation can be either intrinsically or extrinsically stimulated, depending on whether an assigned activity is performed for the sake of the activity itself or for reasons which are external to the activity. Therefore, a number of studies have confirmed that gamification is consistently positioned as a technological tool to facilitate extrinsic and intrinsic motivation, which, in turn, helps individuals accomplish their specific tasks through the selective use of game elements [12].

Thus, motivational behavior including enjoyment and flow experience can be prompted, to a significant degree, by stimulating the human need for competence, autonomy and social relatedness, which may be generated by game design elements such as challenges, missions, rewards, and quizzes. Furthermore, in many common gamified contexts, such as learning or emulating healthy behavior, the activities require a long-term commitment and persistence for the results to actualize [3]. On the other hand, gamified systems feature hedonic designs and aim at making the process of using the system enjoyable [26].

Keeping in mind the aforementioned discussion, gamification is conceptualized in Figure 1; here it consists of three constructs: affordance, psychological outcome, and behavioral outcome [3,21,29]. Affordance refers to a variety of game elements and mechanics such as missions or awards, and it is 
expected to induce experiences which lead to psychological outcomes. Psychological outcomes refer to psychological experiences such as enjoyment, engagement, flow or autonomy which game designs are commonly considered to promote. Behavioral outcomes refer to behaviors that are gained through the use of gamification, such as increased knowledge or better learning outcomes.

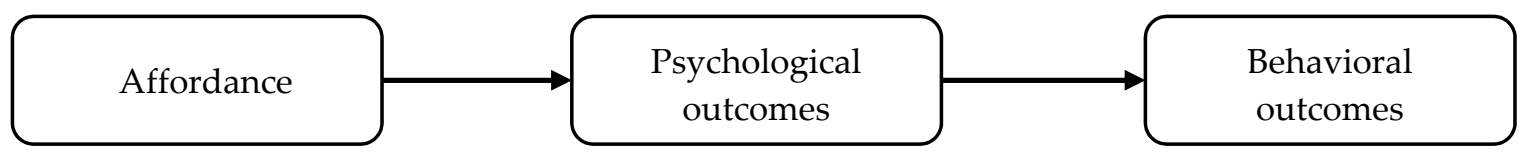

Figure 1. Conceptualization of gamification effect by Huotari \& Hamari [24].

\subsubsection{Gamification, and Enjoyment and Flow}

In the tourism environment, gamification can add fun to traveling, as it animates the experience and enables users to engage with the destination in an interactive way [44]. Gamification activities encompass challenges and tasks yielding psychological tension or stress in an interval process, which, in turn, helps users to focus primarily on the destination or attraction itself without external intervention. The tension generated by missions and challenges in gamification causes positive stress, called eustress $[45,46]$, which is associated with positive emotions such as joy, contentment, and excitement. When starting a game, a gamification user accepts the contingency of the end result; however, the process is expected to be enjoyable, regardless of the outcome. Unique features of gamified apps also include controlling the time for relaxation and creating new missions and tasks in specific situations. The continuous change between tension and relaxation is an important source of user enjoyment and flow experience [47].

Given the significant role of gamification from the theoretical and practical perspectives, gamified app users exploring historical tourist sites (e.g., Gyeongbok palace) are able to experience a series of missions and challenges in step-by-step stages which range from easy to difficult. Specifically, users are asked to complete a set of sections in a sequence: (1) they participate in a mission task to acquire historic knowledge about an assigned heritage attraction, and (2) they feel relaxation while preparing for a subsequent task. The 'tension and release' stages are repeated, consequently leading to enjoyment and higher levels involvement in learning attraction features.

The theory of flow, coined by Csikszentmihlyi [48], provides a theoretical framework for explaining the effect of gamification on the learning benefits of travel experiences. Flow refers to "the state in which people are so involved in an activity that nothing else seems to matter; the experience itself is so enjoyable that people will do it even at great cost, for the sheer sake of doing it" (p. 4). Csikszentmihalyi stated that people cannot usually force themselves to enter a state of flow, but rather, it happens when someone gets involved in an activity for intrinsic motivation that gamification is mainly targeting. In this regard, numerous studies on gamification (e.g., [18,49-51]) have demonstrated the role of gamification in diverse contexts such as tourism, showing the effect of gamified apps featuring design elements with clear goals, missions, and immediate feedback on enhancing the magnitude of enjoyment and flow vis-a-vis cultural heritage sites.

Therefore, this study hypothesizes that:

Hypothesis 1 (H1). Gamification has a positive effect on the level of tourist enjoyment in cultural heritage sites.

Hypothesis 2 (H2). Gamification has a positive effect on the level of tourist flow experience in cultural heritage sites.

\subsubsection{Gamification and Knowledge Gain}

As mentioned above, numerous studies have demonstrated the positive impact of gamification interventions on learning outcomes (e.g., knowledge level). Game features such as tasks, quests and 
missions provide players with the possibility of learning new skills with clear goals which can foster transparency [26].

In this line, gaming can enhance tourists' levels of interest in a destination by providing memorable experiences and knowledge which would otherwise not be available [5]. As game design is usually based on a real environment, like a tourism site; this provides potential visitors with an informative and entertaining setting. Most gamified tourism apps use a training system for effective information delivery that clearly informs visitors of the roles that they will be given in advance, and continually provides visitors with a variety of missions and quizzes [13]. With such continuous information transmission and guidance, it is anticipated that the gamification users acquire clearer information, as intended by the information provider, in comparison with non-gamification users, consequently enhancing the level of knowledge of the destination [40].

More importantly, game design elements such as hints, quizzes, direction information, and geocaching (e.g., finding treasure using geographic information) can be utilized for visitors to access systematic information about attractions. In this regard, some studies have demonstrated that the function of real-time feedback allows users to recognize their progress and gain information in a timely manner, which, in turn, can facilitate the level of knowledge gain about evaluative places or attractions $[19,52]$.

Therefore, this study hypothesizes:

Hypothesis 3 (H3). Gamification has a positive effect on knowledge gain about cultural heritage sites.

\subsubsection{Gamification, Flow and Enjoyment, and Loyalty}

Loyalty refers to the degree of attachment that a consumer has for a certain brand, or the favorable attitude toward a product or service. Loyalty toward a given destination or attraction is defined as the extent to which an individual is more attached to a destination, including revisit intention or the intention to promote the site by positive word-of-mouth (WOM) feedback [53,54]. The level of loyalty and satisfaction with a destination vary depending on the degree of tourist involvement and commitment that are generated in the process of information acquisition [13,41]. While touring sites of interest, information and memorable experiences drawn from game design elements are directly linked to loyalty, such as behavioral and WOM intentions [19]. When the use of gamification in a destination is enjoyable, the chances of engaging with it long-term can be increased $[6,55,56]$, which, in turn, may reinforce the level of behavioral outcomes such as loyalty toward destination sites. More importantly, Lucassen and Jansen [37] confirmed that gamification is regarded as a key tool for the promotion of core marketing consequences such as active participation, brand awareness, and brand loyalty. They also verified that the rewards of gamified elements play a critical role in promoting the formation of long-term memories, thereby enhancing the magnitude of loyalty toward given sites.

Keeping in mind the aforementioned theoretical evidence, this study hypothesizes:

Hypothesis 4 (H4). Flow has a positive effect on knowledge gain about cultural heritage sites.

Hypothesis 5 (H5). Enjoyment has a positive effect on knowledge gain about cultural heritage sites.

Hypothesis 6 (H6). Gamification in cultural heritage sites has a positive effect on loyalty.

Hypothesis 7 (H7). Flow has a positive effect on loyalty toward cultural heritage sites.

Hypothesis 8 (H8). Enjoyment has a positive effect on loyalty toward cultural heritage sites.

Hypothesis 9 (H9). The increased level of knowledge which results from gamification has a positive effect on loyalty toward cultural heritage sites. 


\section{Methodology}

\subsection{Research Method}

Given a comprehensive review of the literature on gamification in SDT and behavioral research, this study proposes a research model, as shown in Figure 2. The proposed research model stresses that the use of gamification should be a significant predictor of visitor motivational factors such as flow, enjoyment, and loyalty. Subsequently, the model also underlines the notion that the use of gamification leads to higher levels of knowledge gain, thereby enhancing levels of loyalty toward cultural heritage sites.

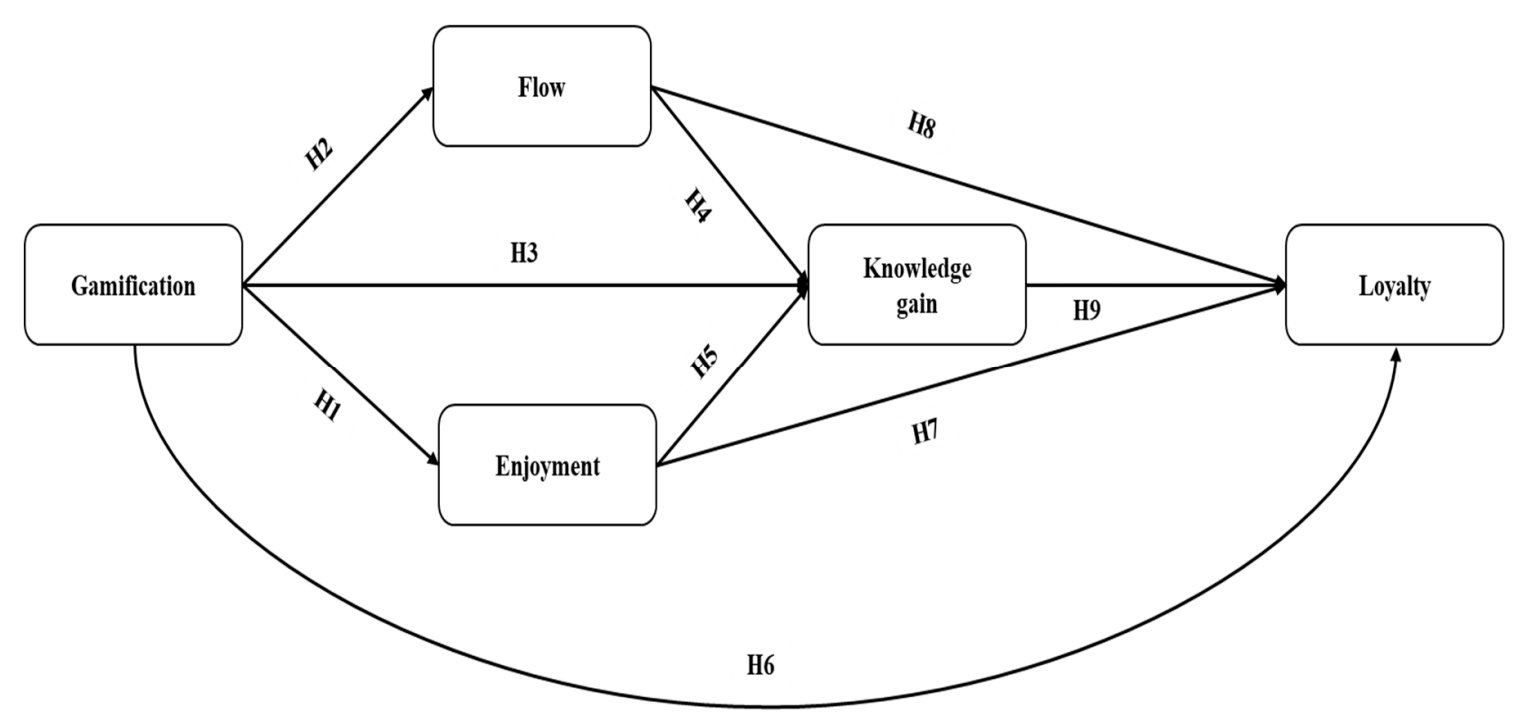

Figure 2. Proposed research model.

\subsection{Context and Design}

The current study used an experimental design method to reach the proposed hypotheses. As a target case for completing a field experiment about the use of gamification, Gyeongbok Palace was selected as a representative cultural heritage site in S. Korea. Gyeongbok Palace is known as the first and largest of the cultural heritage site in S. Korea. Built in 1395, it was located at the heart of the newly-appointed capital, Seoul, and embodied the sovereignty of the Joseon Dynasty. Visitors enjoy looking at the architectural variations among buildings, each of which serves a unique purpose. In addition, even before entering the palace, tourists enjoy gathering at the Gwanghwamun Gate to watch the Royal Guard Changing Ceremony.

As shown in Figure 3, 'Gyeongbok Palace in My Hand', a multimodal gamified application that enables users to experience real-time information about cultural heritage sites, was employed experimentally in this study. The overall objective of the gamified app was to support cultural heritage teaching and learning, thereby enhancing visitors' experiences. Given the functionality of gamification, gamified app users can (a) experience game design elements consisting of rewards, missions, and quizzes, (b) switch between modes of exploring cultural and historical information, and (c) access global positioning system (GPS) information and an augmented reality (AR), 3D unmanned guidance system. The technology integrates a location-based service with object-based sensors for artifacts at historic sites. Visitors explore such sites while interacting with artifacts to complete missions. The object is synthesized using image recognition technologies from images received via their smartphone camera. Given the function of cultural heritage interpretation in gamification, visitors can not only obtain general information on the facilities and history of the site from gamified apps, but can also collect real-time information about ongoing events and programs as if a guide were present. 


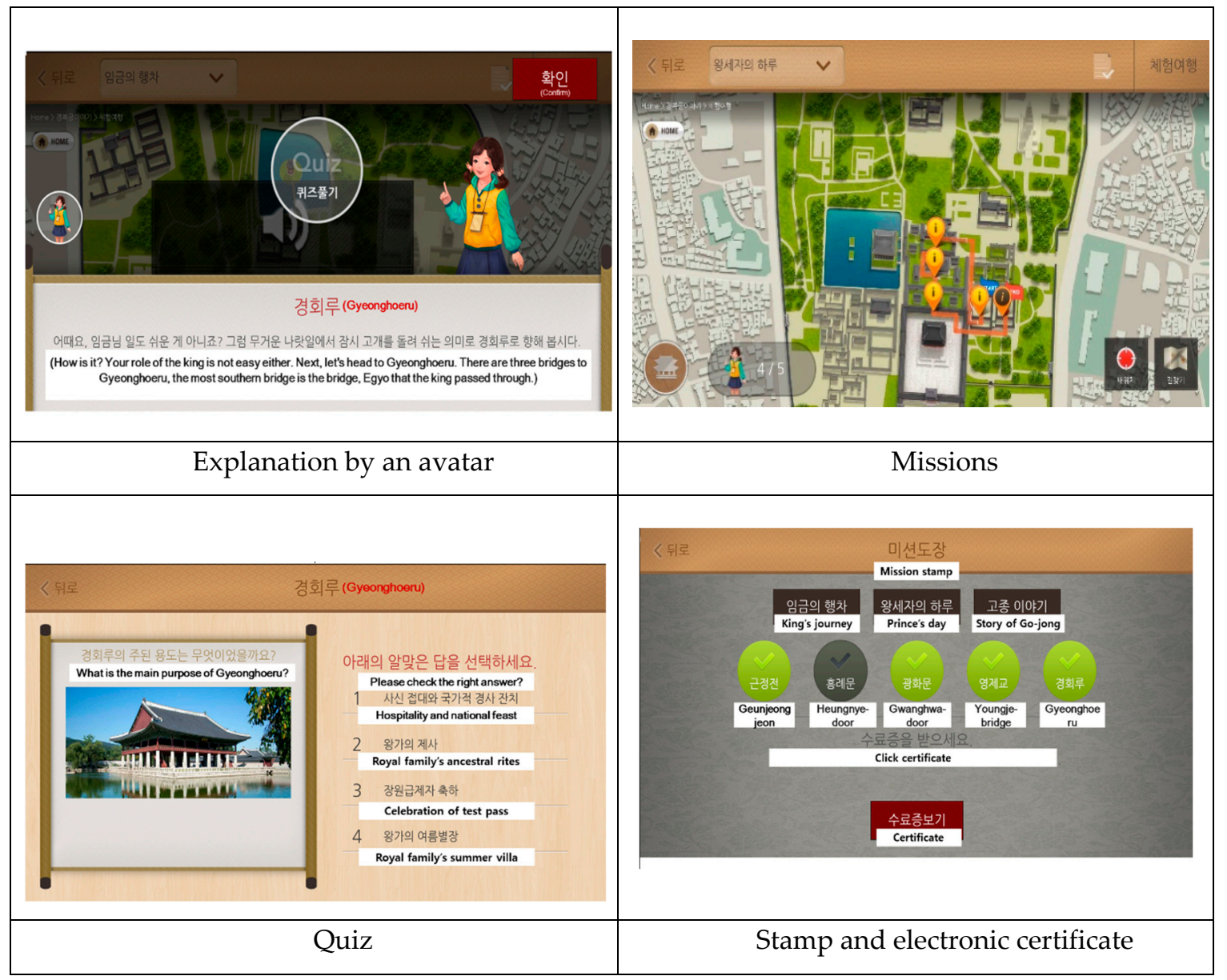

Figure 3. Gamified application-'Gyeongbok Palace in My Hands'.

Gamified app contents, i.e., images, texts, and videos, are optimized for smartphones. Considering the various types of visitors to cultural heritage sites, the application stimulates the visitor to look at cultural heritage elements in three different modes, permitting the construction of personal narratives while creating a personal narrative: general mode, time travel mode, and experiential trip mode. Importantly, the app includes diverse game elements such as stamps, missions, quizzes, and rewards.

Once visitors arrive at a historical place or facility, they can learn essential information about the attractions through gamified apps or on-site information sources. In terms of knowledge gain, visitors are asked to take a series of quizzes or missions. For example, visitors are asked to take an assigned image of attractions at a given stage, and are then allowed to move to the next location. Once app users have finished all the missions or quizzes at each stage, an electronic certificate is awarded.

\subsection{Participants and Procedure}

As subjects of this study, 342 undergraduate students were selected by a stratified random sampling method from among students majoring in tourism at a university of South Korea. The use of college students as a sample for the experience is appropriate, because the majority of gamified application users are in their 20s. In order to invite research participants, a letter of recruitment was posted on the bulletin board and homepage of the department. The letter described the research purpose and participation benefits, i.e., free entrance to the Gyeongbok Palace (worth $\$ 5$, as well as a gift card worth \$5). In addition, it was announced that they would be randomly assigned to either the gamified app user group or non-user group. However, those who did not want to use the gamified app were assigned to the non-user group. Data were collected from 15-25 April 2017. To guarantee similar conditions for all participants, the tour schedule was limited to weekday afternoons (1-5 pm) when 
special events were not being held. The gamified app user group started the tour after participating in an introductory session explaining how they should install and use the gamified app while touring the site, while the non-user group was asked to freely tour Gyeongbok palace without any intervention. All participants, regardless of whether or not they were using the app, were assessed on their level of knowledge about Gyeongbok palace prior to their tour. Importantly, there were no mean differences in pre-knowledge levels between the gamified app user group and the non-user group $(t=1.546$, $p=0.123$ ).

In a subsequent process, the knowledge level of the participants was re-measured as soon as the tour was over. Samples of 342 participants were randomly assigned to the gamification user group (165) and non-user group (177). Due to a malfunction of the app, 11 cases were excluded from the analysis. As a result, a total of 331 samples were used for analysis (gamification user group: 160, non-gamification user group: 171). Of the sample, 155 were male and 176 were female. The mean age was 22.

\subsection{Measurements}

Knowledge level was measured using a scaled questionnaire, with the question: 'Please indicate the current level of your knowledge of Gyeongbok palace'. The value of knowledge gain was obtained by subtracting the value before and after the visit [Mean difference: $1.39(\mathrm{t}=13.458, p<0.001)$; mean value after the tour: 6.25; mean value before the tour: 4.86].

As shown in Table 1, the scales of flow were adapted and modified from Chang [57] and Skadberg and Kimmel [58]. Participant flow experience was assessed by three items with a 7 point scale system. Enjoyment was measured by four items adapted by Wu [59] and Yang, Asaad, and Dwivedi [8]. Regarding destination loyalty, four items were employed to gauge the level of loyalty toward Gyeongbok palace; these items were adapted and modified from previous studies [60-62].

Table 1. Reliability and validity test.

\begin{tabular}{|c|c|c|c|c|}
\hline Factors & $\begin{array}{l}\text { Factor } \\
\text { Loadings }\end{array}$ & Eigenvalue & $\begin{array}{c}\text { Variance } \\
\text { Explained }(\%)\end{array}$ & Cronbach's $\alpha$ \\
\hline Enjoyment & & 6.378 & 57.985 & 0.947 \\
\hline The tour was exciting & 0.873 & & & \\
\hline The tour was interesting & 0.840 & & & \\
\hline The tour gave me a lot of pleasure & 0.839 & & & \\
\hline The tour was enjoyable & 0.808 & & & \\
\hline Loyalty & & 1.236 & 11.233 & 0.852 \\
\hline $\begin{array}{l}\text { I may recommend Gyeongbok palace to } \\
\text { other people. }\end{array}$ & 0.830 & & & \\
\hline I may re-visit Gyeongbok palace. & 0.819 & & & \\
\hline $\begin{array}{l}\text { The tour compels me to visit other cultural } \\
\text { heritage sites like Gyeongbok palace }\end{array}$ & 0.767 & & & \\
\hline $\begin{array}{l}\text { I would like to know more about } \\
\text { Gyeongbok palace }\end{array}$ & 0.673 & & & \\
\hline Flow & & 1.028 & 9.349 & 0.850 \\
\hline $\begin{array}{l}\text { I was not conscious of the flow of time while } \\
\text { touring Gyeongbok palace }\end{array}$ & 0.864 & & & \\
\hline $\begin{array}{l}\text { While touring Gyeongbok palace, I had a } \\
\text { feeling of concentration }\end{array}$ & 0.777 & & & \\
\hline $\begin{array}{l}\text { I could not think about anything other than } \\
\text { Gyeongbok palace during the tour }\end{array}$ & 0.752 & & & \\
\hline
\end{tabular}




\section{Results}

The proposed research model requires a mediation analysis to determine whether the size of the effect of the use of gamification on loyalty to Gyeongbok palace is influenced by multiple mediator variables, flow, enjoyment, and knowledge gain. Thus, the hypotheses were tested by a PROCESS modeling technique (model 80) proposed by Hayes [63]. In that the current research is based on a serial multiple mediator analysis, the PROCESS technique was considered suitable, as it generates bootstrap confidence intervals for all indirect effects, as well as all possible pairwise comparisons between indirect effects using 5000 bootstrap samples.

Prior to testing the hypotheses, the reliability and construct validity for items of flow, enjoyment, and loyalty were assessed. Table 1 presents the results of the factor analysis using varimax rotation. The Kaiser-Meyer-Olkin (KMO) measure confirmed the sampling adequacy for further analysis (KMO $=0.76$, i.e., well above the recommended limit of 0.5) [64]. The values of Cronbach's Alpha for each factor were more than 0.850 , which indicates a high level of internal consistency and reliability for the scale.

\section{Hypotheses Test}

As seen in Table 2, the use of gamification showed a negative effect on visitor flow experience, i.e., those assigned to the gamification user group were, on average, 0.694 units lower in their flow than those assigned to the non-gamification group. Similar to this result, gamification was also shown to have a negative impact on enjoyment. That is, non-gamification users showed higher levels of enjoyment than gamification users.

Table 2. Effect of gamification on flow and enjoyment.

\begin{tabular}{cccccc}
\hline DV & IV & Coefficient & SE & T & $p$ \\
\hline \multirow{2}{*}{ Flow } & Constant & 5.055 & 0.103 & $49.040^{* *}$ & 0.000 \\
& Gamification & -0.694 & 0.149 & $-4.674^{* *}$ & 0.000 \\
\hline \multirow{2}{*}{ Enjoyment } & Constant & 5.953 & 0.083 & $71.514^{* *}$ & 0.000 \\
& Gamification & -0.882 & 0.120 & $-7.352^{* *}$ & 0.000 \\
\hline
\end{tabular}

Flow: $\mathrm{R}=0.251, R^{2}=0.063, \mathrm{~F}=21.846(p<0.001)$; Fun: $\mathrm{R}=0.378, R^{2}=0.142, \mathrm{~F}=54.049(p<0.001)$; ${ }^{* *} p<0.001$.

Coding indicator: gamification users $=1$, non-gamification users $=0$.

Table 3 shows the results of the direct effects of gamification, flow, and enjoyment on knowledge gain. As shown in Table $3, R^{2}=0.120, \mathrm{~F}=14.731(p<0.001)$, gamification $(\beta=1.276, p<0.001)$ and enjoyment $(\beta=0.455, p<0.01)$ had significant effects on knowledge gain, implying that gamification can be utilized as a strong facilitator of knowledge acquisition; furthermore, the group using gamification showed 1276 units of higher knowledge increase effect compared to the non-gamification group. These results may explain why gamification is frequently used in the field of education or learning. Although gamification had negative effects on flow and enjoyment, gamified app users perceived a higher level of knowledge gain than the non-gamified app user group.

Table 3. Effect of gamification on knowledge gain.

\begin{tabular}{cccccc}
\hline DV & IV & Coefficient & SE & T & $p$ \\
\hline \multirow{3}{*}{ Knowledge gain } & Constant & -1.634 & 0.562 & $-2.908^{* *}$ & 0.003 \\
& Gamification & 1.276 & 0.212 & $6.020^{* *}$ & 0.000 \\
\cline { 2 - 6 } & Flow & -0.022 & 0.089 & -0.243 & 0.808 \\
& Enjoyment & 0.455 & 0.110 & $4.145^{* *}$ & 0.01 \\
\hline
\end{tabular}

$\mathrm{R}=0.346, R^{2}=0.120, \mathrm{~F}=14.731(p<0.001),{ }^{* *} p<0.001$. Coding indicator: gamification users $=1$, non-gamification users $=0$. 
As shown in Table 4, gamification did not increase the degree of loyalty toward cultural heritage sites. However, flow $(\beta=0.152, p<0.001)$ and enjoyment $(\beta=0.459, p<0.001)$ were shown to have significant effects on loyalty. Interestingly, the effect of knowledge gain on loyalty was also not significant. These findings indicate that knowledge gain is a strong factor encouraging visitors to tour cultural heritage sites, whereas enjoyment in gamification is a salient predictor for facilitating loyalty toward cultural heritage sites.

Table 4. The effect of gamification on loyalty.

\begin{tabular}{lccccc}
\hline DV & IV & Coefficient & SE & T & $p$ \\
\hline \multirow{3}{*}{ Loyalty } & Constant & 2.179 & 0.252 & 8.650 ** & 0.000 \\
\cline { 2 - 5 } & Gamification & 0.0735 & 0.099 & 0.744 & 0.458 \\
\cline { 2 - 5 } & Flow & 0.152 & 0.039 & $3.882 * *$ & 0.000 \\
\cline { 2 - 5 } & Enjoyment & 0.459 & 0.050 & $9.202 * *$ & 0.000 \\
\cline { 2 - 5 } & Knowledge gain & 0.016 & 0.025 & 0.663 & 0.508 \\
\hline $\begin{array}{l}\mathrm{R}=0.655, R^{2}=0.429, \mathrm{~F}=60.648(p<0.001),{ }^{* *} p<0.001 \text {. Coding indicator: gamification users }=1 \text {, non-gamification } \\
\text { users }=0 .\end{array}$
\end{tabular}

Table 5 shows an indirect effect of gamification on loyalty toward cultural heritage sites by Boostrapping. The results indicate that the total effect of gamification on loyalty is negative $(\beta=$ -0.496, $p<0.05$ ), and that two indirect paths (gamification-flow-loyalty, $\beta=-0.106, p<0.05$ ); gamification-enjoyment-loyalty, $\beta=-0.404, p<0.05$ ) are negatively significant. These findings reveal that both enjoyment and flow have positive effects on loyalty, while gamification negatively and indirectly influences loyalty toward cultural heritage sites.

Table 5. Indirect effects of gamification on loyalty.

\begin{tabular}{lcccc}
\hline \multicolumn{1}{c}{ Path } & Effect & BootSE & BootLLCI & BootULCI \\
\hline Total & -0.496 & 0.089 & -0.675 & -0.323 \\
\hline Gamification-Flow-Loyalty & -0.106 & 0.044 & -0.203 & -0.033 \\
\hline Gamification-Enjoyment-Loyalty & -0.404 & 0.082 & -0.576 & -0.255 \\
\hline Gamification-Knowledge Gain-Loyalty & 0.021 & 0.030 & -0.038 & 0.080 \\
\hline Gamification-Flow-Knowledge Gain-Loyalty & 0.001 & 0.002 & -0.004 & 0.005 \\
\hline Gamification-Enjoyment-Knowledge Gain-Loyalty & -0.007 & 0.011 & -0.032 & 0.010 \\
\hline \multicolumn{2}{c}{ 95\% bootstrap confidence. } \\
\end{tabular}

\section{Discussion and Conclusions}

\subsection{Discussion}

Using an experimental design method, this study explored the role of gamification on visitor motivational behavior, knowledge gain, and loyalty within a cultural heritage context. Based on a comprehensive review of the literature on gamification in education, marketing, and tourism, the study makes a theoretical contribution to the expansion of the research model on gamification in cultural tourism. To date, empirical studies on gamification in tourism have been limited to conceptual works, with the exception of the study of Sigala [13]. In this regard, the present study provides support for empirical evidence on gamification-related models and theories such as SDT, based on experimental methods, in cultural tourism.

With regard to theoretical contributions, this study found negative effects of gamification on visitor motivational behavior, which is inconsistent with the findings of previous studies proposing a positive role therein. Despite limited empirical evidence on the role of gamification within the context 
of tourism, there is a general assumption that gamification has a positive effect on tourist motivational behavior, i.e., flow, enjoyment, autonomy, positive emotion, etc.

However, this study found that gamification had a negative effect on visitor enjoyment and flow experience. Furthermore, the use of gamification was found to have a negative indirect effect on visitor loyalty. This study also demonstrated that both enjoyment and flow play significant roles in enhancing the level of knowledge gain in gamification environments. As unexpected, both gamification and knowledge gain did not have direct influences on loyalty toward cultural heritage sites. However, gamification had the greatest influence on knowledge gain. This finding related to the learning effects of gamification is well supported by task-based learning theory. The theory focuses on the relationship between cognitive tasks and information-rich virtual environments. It emphasizes how games appear to be particularly suited as supports for the study of images such as those associated with tourist destinations. Compared to reading text, a game forces the visitors to focus more intensively on problems, which favors knowledge acquisition and retention.

From a managerial perspective, gamification had a negative effect on flow and enjoyment, which is inconsistent with the findings of previous studies highlighting the theoretical aspects of SDT (e.g., $[45,60,61])$, demonstrating the positive effect of gamification on motivational behaviors. This result may stem from situations with which individuals are unfamiliar, i.e., the process of performing assigned missions and quizzes on heritage, history, and so on, in a gamification environment. It appears that gamified app users may become stressed while performing unfamiliar tasks such as quizzes or missions, because gamified app users may feel that the assigned tasks may be difficult at their knowledge level. As for ways to overcome this problem, the operators of gamified apps are encouraged to develop customized design elements by considering various types of demographic groups (e.g., different generations, gender, etc.) within a given context. Furthermore, as SDT indicates, autonomy is a key factor for facilitating psychological motivation. However, gamified app users may experience a low level of self-control (i.e., autonomy) which is strongly associated with enjoyment or flow, in the sense that they are not allowed to manage the use of gamified app contents and are asked to follow the guidelines (e.g., the order of taking tasks) outlined in gamified apps. In summary, it is important to find an optimal balance between user perceived skills and the level of missions or challenges when it comes to creating well-designed gamified apps which can augment the level of enjoyment and flow experience in a given tourism context [65]. In this line, it may be possible that gamification users felt that some missions were difficult relative to their current level of knowledge. Thus, the tension generated by missions and challenges in gamification may cause negative stress.

The current study has important practical implications for tourism facilities, attractions, and destinations such as cultural heritage sites. This study does not deny the benefits of gamification on visitor experience, but underlines the hypothesis that the operators of gamified apps are required to control missions and the levels of quizzes, consequently reducing the degree of motivational states (e.g., enjoyment and flow). As Schell [47] stressed, when people are too relaxed during the use of the application, they feel bored, and when they experience too much tension, they feel worn out. Therefore, it is imperative to move often between boredom and tension in order to offer variety on one hand, and the pleasure of anticipation on the other.

Despite the result that gamification had a negative effect on enjoyment and flow, gamified app users were found to have a higher level of knowledge gain than that of non-users. This result may be due to the phenomenon that operators of cultural heritage sites (e.g., Gyeongbok palace) are faced with difficulties in conveying complex historical information and knowledge to visitors in an effective manner. In this sense, cultural heritage sites are often regarded as inactive and boring, and, as a result, some demographic groups (e.g., young people) are often reluctant to visit them. Therefore, this study demonstrated that gamification is an efficient and useful tool for tourism destinations where interactive information and knowledge should be shared.

However, it is worth noting that neither gamification nor increased knowledge directly influenced visitor loyalty to Gyeongbok palace. This result implies that gamified app users are unlikely to 
spend more time enjoying a cultural heritage site in an effort to acquire the variety of information provided to them to help in performing missions, which, in turn, would make them feel as if they were being educated. Given the fact that both flow and enjoyment had positive effects on loyalty vis-a-vis cultural heritage sites, practitioners need to design apps including fun elements (e.g., 3D and AR) that help reinforce flow experience. That is, an over-reliance on missions and rewards to facilitate visitor knowledge gain may result in negative outcomes regarding loyalty.

\subsection{Conclusions and Limitations}

In sum, this study emphasizes the critical aspects by which gamification can enhancing visitors' experiences. That is, it might be a better way to provide gamification as one of the various tour options that visitors freely choose. Nevertheless, the critical effect of gamification on fostering the level of education should not be overlooked. Under the circumstance that those who visit an unfamiliar destination site are willing to learn about it, the use of gamification may ensure that this goal is achieved. When it comes to the increasing demand for historical knowledge gain by middle or high school students visiting cultural heritage sites, gamification has the potential to serve as an effective tool.

Despite its contributions, this study has some limitations. First, the research participants were limited to college students who are not actual cruise tourists, and therefore, may not represent the various demographics of cruise tourists visiting cultural heritage sites. Although the majority of gamification users were in their 20s, it is important to determine whether the effect of gamification, including game design elements, varies, depending on the different age groups of users. Therefore, the results of this study should not be overly generalized. Second, although this study verified the overall effect of gamification, it could not verify specifically what kinds of game design elements play important roles in facilitating visitor motivational behavior and knowledge gain. Thus, future study is recommended to test the impact of specific game design elements such as rewards, missions, and stamps.

Lastly, this study considered only gamified app users and non-users. However, it is rare for visitors to focus solely on the use of gamified apps while touring tourist sites. In this regard, further research should examine whether there are significant differences between gamified app users and multiple information sources, i.e., gamified app and tour guidebook users, or gamified app and tour guide users. It is possible that visitors will perceive different levels of involvement in the use of gamification. Thus, it is necessary for future researchers to consider different effects according to the degree of gamification use.

Funding: This work was supported by Kyonggi University Research Grant 2016.

Conflicts of Interest: The author declares no conflict of interest.

\section{References}

1. Johnson, D. Environmentally Sustainable Cruise Tourism: A Reality Check. Mar. Policy 2002, 26, 261-270. [CrossRef]

2. Georgsdottir, I.; Oskarsson, G. Segmentation and Targeting in the Cruise Industry: An Insight from Practitioners Serving Passengers at the Point of Destination. Bus. Manag. Rev. 2017, 8, 350-364.

3. Koivisto, J.; Hamari, J. The Rise of Motivational Information Systems: A Review of Gamification Research. Int. J. Inf. Manag. 2019, 45, 191-210. [CrossRef]

4. Gentes, A.; Guyot-Mbodji, A.; Demeure, I. Gaming on the Move: Urban Experience as a New Paradigm for Mobile Pervasive Game Design. Multimed. Syst. 2010, 16, 43-55. [CrossRef]

5. Xu, F.; Tian, F.; Buhalis, D.; Weber, J.; Zhang, H. Tourists as Mobile Gamers: Gamification for Tourism Marketing. J. Travel Tour. Mark. 2015, 33, 1124-1142. [CrossRef]

6. Kankanhalli, A.; Taher, M.; Cavusoglu, H.; Kim, S. Gamification: A New Paradigm for Online User Engagement. In Proceedings of the International Conference on Information Systems, ICIS 2012, Orlando, FL, USA, 16-19 December 2012. 
7. Deterding, S.; Dixon, D.; Khaled, R.; Nacke, L. From Game Design Elements to Gamefulness: Defining "Gamification". In Proceedings of the 15th International Academic MindTrek Conference: Envisioning Future Media Environments, Tampere, Finland, 28-30 September 2011; ACM: New York, NY, USA, 2011; pp. 9-15. [CrossRef]

8. Yang, Y.; Asaad, Y.; Dwivedi, Y. Examining the Impact of Gamification on Intention of Engagement and Brand Attitude in the Marketing Context. Comput. Hum. Behav. 2017, 73, 459-469. [CrossRef]

9. Hammady, R.; Ma, M.; Temple, N. Augmented Reality and Gamification in Heritage Museums. In Serious Games; Marsh, T., Ma, M., Oliveira, M.F., Baalsrud Hauge, J., Göbel, S., Eds.; Lecture Notes in Computer Science; Springer International Publishing: Cham, Switzerland, 2016; pp. 181-187.

10. Liarokapis, F.; Petridis, P.; Andrews, D.; de Freitas, S. Multimodal Serious Games Technologies for Cultural Heritage. In Mixed Reality and Gamification for Cultural Heritage; Ioannides, M., Magnenat-Thalmann, N., Papagiannakis, G., Eds.; Springer International Publishing: Cham, Switzerland, 2017; pp. 371-392. [CrossRef]

11. Anderson, E.F.; McLoughlin, L.; Liarokapis, F.; Peters, C.; Petridis, C.; de Freitas, S. Serious Games in Cultural Heritage. In Proceedings of the 10th International Symposium on Virtual Reality, Archaeology and Cultural Heritage VAST—State of the Art Reports, Valletta, Malta, 22-25 September 2009; pp. 29-84.

12. Seaborn, K.; Fels, D.I. Gamification in Theory and Action: A Survey. Int. J. Hum. -Comput. Stud. 2015, 74, 14-31. [CrossRef]

13. Sigala, M. Applying Gamification and Assessing Its Effectiveness in a Tourism Context: Behavioural and Psychological Outcomes of the Tripadvisor's Gamification Users. Asia Pac. J. Inf. Syst. 2015, 25, 179-210. [CrossRef]

14. Foster, J.A.; Sheridan, P.K.; Irish, R.; Frost, G.S. Gamification as a Strategy for Promoting Deeper Investigation in a Reverse Engineering Activity. In Proceedings of the 2012 ASEE Annual Conference \& Exposition, San Antonio, TX, USA, 10-13 June 2012.

15. Goehle, G. Gamification and Web-Based Homework. Primus 2013, 23, 234-246. [CrossRef]

16. Hanus, M.D.; Fox, J. Assessing the Effects of Gamification in the Classroom: A Longitudinal Study on Intrinsic Motivation, Social Comparison, Satisfaction, Effort, and Academic Performance. Comput. Educ. 2015, 80, 152-161. [CrossRef]

17. Domínguez, A.; Saenz-de-Navarrete, J.; de-Marcos, L.; Fernández-Sanz, L.; Pagés, C.; Martínez-Herráiz, J.-J. Gamifying Learning Experiences: Practical Implications and Outcomes. Comput. Educ. 2013, 63, 380-392. [CrossRef]

18. Xu, F.; Weber, J.; Buhalis, D. Gamification in Tourism. In Information and Communication Technologies in Tourism 2014; Xiang, Z., Tussyadiah, I., Eds.; Springer International Publishing: Cham, Switzerland, 2013; pp. 525-537. [CrossRef]

19. Bulencea, P.; Egger, R. Gamification in Tourism: Designing Memorable Experiences; Books on Demand: Norderstedt, Germany, 2015.

20. Salen, K.; Tekinbaş, K.S.; Zimmerman, E. Rules of Play: Game Design Fundamentals; MIT Press: Cambridge, MA, USA, 2004.

21. Hamari, J.; Koivisto, J.; Sarsa, H. Does Gamification Work?-A Literature Review of Empirical Studies on Gamification. In Proceedings of the 2014 47th Hawaii International Conference on System Sciences, Waikoloa, HI, USA, 6-9 January 2014; pp. 3025-3034. [CrossRef]

22. Xi, N.; Hamari, J. Does Gamification Satisfy Needs? A Study on the Relationship between Gamification Features and Intrinsic Need Satisfaction. Int. J. Inf. Manag. 2019, 46, 210-221. [CrossRef]

23. Hamari, J. Do Badges Increase User Activity? A Field Experiment on the Effects of Gamification. Comput. Hum. Behav. 2017, 71, 469-478. [CrossRef]

24. Mekler, E.D.; Brühlmann, F.; Tuch, A.N.; Opwis, K. Towards Understanding the Effects of Individual Gamification Elements on Intrinsic Motivation and Performance. Comput. Hum. Behav. 2017, 71, 525-534. [CrossRef]

25. Mitchell, R.; Schuster, L.; Jin, H.S. Gamification and the Impact of Extrinsic Motivation on Needs Satisfaction: Making Work Fun? J. Bus. Res. 2018. [CrossRef]

26. Sailer, M.; Hense, J.U.; Mayr, S.K.; Mandl, H. How Gamification Motivates: An Experimental Study of the Effects of Specific Game Design Elements on Psychological Need Satisfaction. Comput. Hum. Behav. 2017, 69, 371-380. [CrossRef] 
27. Werbach, K.; Hunter, D. For the Win: How Game Thinking Can Revolutionize Your Business; Wharton Digital Press: Philadelphia, PA, USA, 2012.

28. Vesa, M.; Hamari, J.; Harviainen, J.T.; Warmelink, H. Computer Games and Organization Studies. Organ. Stud. 2017, 38, 273-284. [CrossRef]

29. Huotari, K.; Hamari, J. A Definition for Gamification: Anchoring Gamification in the Service Marketing Literature. Electron Mark. 2017, 27, 21-31. [CrossRef]

30. Urh, M.; Vukovic, G.; Jereb, E.; Pintar, R. The Model for Introduction of Gamification into E-Learning in Higher Education. Procedia Soc. Behav. Sci. 2015, 197, 388-397. [CrossRef]

31. Dias, J. Teaching Operations Research to Undergraduate Management Students: The Role of Gamification. Int. J. Manag. Educ. 2017, 15, 98-111. [CrossRef]

32. King, D.; Greaves, F.; Exeter, C.; Darzi, A. 'Gamification': Influencing Health Behaviours with Games. J. R. Soc. Med. 2013, 106, 76-78. [CrossRef]

33. Johnson, D.; Deterding, S.; Kuhn, K.-A.; Staneva, A.; Stoyanov, S.; Hides, L. Gamification for Health and Wellbeing: A Systematic Review of the Literature. Internet Interv. 2016, 6, 89-106. [CrossRef]

34. Lister, C.; West, J.H.; Cannon, B.; Sax, T.; Brodegard, D. Just a Fad? Gamification in Health and Fitness Apps. JMIR Serious Games 2014, 2, e9. [CrossRef]

35. Morschheuser, B.; Hamari, J. The Gamification of Work: Lessons from Crowdsourcing. J. Manag. Inq. 2019, 28, 145-148. [CrossRef]

36. Perryer, C.; Celestine, N.A.; Scott-Ladd, B.; Leighton, C. Enhancing Workplace Motivation through Gamification: Transferrable Lessons from Pedagogy. Int. J. Manag. Educ. 2016, 14, 327-335. [CrossRef]

37. Lucassen, G.; Jansen, S. Gamification in Consumer Marketing-Future or Fallacy? Procedia Soc. Behav. Sci. 2014, 148, 194-202. [CrossRef]

38. Hofacker, C.F.; de Ruyter, K.; Lurie, N.H.; Manchanda, P.; Donaldson, J. Gamification and Mobile Marketing Effectiveness. J. Interact. Mark. 2016, 34, 25-36. [CrossRef]

39. Conaway, R.; Garay, M.C. Gamification and Service Marketing. SpringerPlus 2014, 3, 653. [CrossRef]

40. Negruşa, A.L.; Toader, V.; Sofică, A.; Tutunea, M.F.; Rus, R.V. Exploring Gamification Techniques and Applications for Sustainable Tourism. Sustainability 2015, 7, 11160-11189. [CrossRef]

41. Yoo, C.; Kwon, S.; Na, H.; Chang, B. Factors Affecting the Adoption of Gamified Smart Tourism Applications: An Integrative Approach. Sustainability 2017, 9, 2162. [CrossRef]

42. Aguiar-Castillo, L.; Clavijo-Rodriguez, A.; De Saa-Perez, P.; Perez-Jimenez, R. Gamification as An Approach to Promote Tourist Recycling Behavior. Sustainability 2019, 11, 2201. [CrossRef]

43. Ryan, R.M.; Deci, E.L. Intrinsic and Extrinsic Motivations: Classic Definitions and New Directions. Contemp. Educ. Psychol. 2000, 25, 54-67. [CrossRef]

44. Xu, F.; Buhalis, D.; Weber, J. Serious Games and the Gamification of Tourism. Tour. Manag. 2017, 60, $244-256$. [CrossRef]

45. Snodgrass, J.G.; Lacy, M.G.; Dengah, H.J.F.; Batchelder, G.; Eisenhower, S.; Thompson, R.S. Culture and the Jitters: Guild Affiliation and Online Gaming Eustress/Distress. Ethos 2016, 44, 50-78. [CrossRef]

46. McGonigal, J. Reality Is Broken: Why Games Make Us Better and How They Can Change the World; Penguin: London, UK, 2011.

47. Shell, J. The Art of Game Design: A Book of Lenses, 1st ed.; CRC Press: Amsterdam, The Netherlands; Boston, MA, USA, 2008.

48. Csikszentmihalyi, M. Flow: The Psychology of Optimal Experience; Harper \& Row: New York, NY, USA, 1990.

49. Hamari, J.; Koivisto, J. Measuring Flow in Gamification: Dispositional Flow Scale-2. Comput. Hum. Behav. 2014, 40, 133-143. [CrossRef]

50. Bittner, J.V.; Schipper, J. Motivational Effects and Age Differences of Gamification in Product Advertising. J. Consum. Mark. 2014, 31, 391-400. [CrossRef]

51. Hamari, J.; Shernoff, D.J.; Rowe, E.; Coller, B.; Asbell-Clarke, J.; Edwards, T. Challenging Games Help Students Learn: An Empirical Study on Engagement, Flow and Immersion in Game-Based Learning. Comput. Hum. Behav. 2016, 54, 170-179. [CrossRef]

52. Taspinar, B.; Schmidt, W.; Schuhbauer, H. Gamification in Education: A Board Game Approach to Knowledge Acquisition. Procedia Comput. Sci. 2016, 99, 101-116. [CrossRef]

53. Oppermann, M. Tourism Destination Loyalty. J. Travel Res. 2000, 39, 78-84. [CrossRef] 
54. Nam, J.; Ekinci, Y.; Whyatt, G. Brand Equity, Brand Loyalty and Consumer Satisfaction. Ann. Tour. Res. 2011, 38, 1009-1030. [CrossRef]

55. Mäntymäki, M.; Salo, J. Teenagers in Social Virtual Worlds: Continuous Use and Purchasing Behavior in Habbo Hotel. Comput. Hum. Behav. 2011, 27, 2088-2097. [CrossRef]

56. Kim, K.; Ahn, S.J.G. RETRACTED: The Role of Gamification in Enhancing Intrinsic Motivation to Use a Loyalty Program. J. Interact. Mark. 2017, 40, 41-51. [CrossRef]

57. Chang, K.-C. Examining the Effect of Tour Guide Performance, Tourist Trust, Tourist Satisfaction, and Flow Experience on Tourists' Shopping Behavior. Asia Pac. J. Tour. Res. 2014, 19, 219-247. [CrossRef]

58. Skadberg, Y.X.; Kimmel, J.R. Visitors' Flow Experience While Browsing a Web Site: Its Measurement, Contributing Factors and Consequences. Comput. Hum. Behav. 2004, 20, 403-422. [CrossRef]

59. Wu, J. The Effects of Trust and Enjoyment on Intention to Play Online Games. J. Electron. Commer. Res. 2007, 8, 14 .

60. Yoon, Y.; Uysal, M. An Examination of the Effects of Motivation and Satisfaction on Destination Loyalty: A Structural Model. Tour. Manag. 2005, 26, 45-56. [CrossRef]

61. Petrick, J.F.; Morais, D.D.; Norman, W.C. An Examination of the Determinants of Entertainment Vacationers' Intentions to Revisit. J. Travel Res. 2001, 40, 41-48. [CrossRef]

62. Nam, M.; Kim, I.; Hwang, J. Can Local People Help Enhance Tourists' Destination Loyalty? A Relational Perspective. J. Travel Tour. Mark. 2016, 33, 702-716. [CrossRef]

63. Hayes, A.F. Introduction to Mediation, Moderation, and Conditional Process Analysis, Second Edition: A Regression-Based Approach; Guilford Publications: New York, NY, USA, 2017.

64. Field, A. Discovering Statistics Using SPSS; SAGE Publications: Thousand Oaks, CA, USA, 2009.

65. Richter, G.; Raban, D.R.; Rafaeli, S. Studying Gamification: The Effect of Rewards and Incentives on Motivation. In Gamification in Education and Business; Reiners, T., Wood, L.C., Eds.; Springer International Publishing: Cham, Switzerland, 2015; pp. 21-46. [CrossRef]

(C) 2019 by the author. Licensee MDPI, Basel, Switzerland. This article is an open access article distributed under the terms and conditions of the Creative Commons Attribution (CC BY) license (http://creativecommons.org/licenses/by/4.0/). 